\title{
Expression profiles of protein tyrosine kinase genes in human embryonic stem cells
}

\author{
Mi-Young Son, Janghwan Kim, Hyo-Won Han, Sun-Mi Woo, Yee Sook Cho, Yong-Kook Kang \\ and Yong-Mahn $\operatorname{Han}^{1}$
}

Korea Research Institute of Bioscience and Biotechnology (KRIBB), Center for Regenerative Medicine, 52 EoeunDong, Yuseong-Gu, Daejeon 305-806, South Korea and ${ }^{1}$ Department of Biological Sciences and Center for Stem Cell Differentiation, KAIST, 335 Gwahangno, Yuseong-gu, Daejeon 305-701, South Korea

Correspondence should be addressed to Y-K Kang; Email: ykkang@kribb.re.kr

Y-M Han; Email: ymhan@kaist.ac.kr

\begin{abstract}
Complex signaling pathways operate in human embryonic stem cells (hESCs) and are coordinated to maintain self-renewal and stem cell characteristics in them. Protein tyrosine kinases (PTKs) participate in diverse signaling pathways in various types of cells. Because of their functions as key molecules in various cellular processes, PTKs are anticipated to have important roles also in hESCs. In this study, we investigated the roles of PTKs in undifferentiated and differentiated hESCs. To establish comprehensive PTK expression profiles in hESCs, we performed reverse transcriptase PCR using degenerate primers according to the conserved catalytic PTK motifs in both undifferentiated and differentiated hESCs. Here, we identified 42 different kinases in two hESC lines, including 5 non-receptor tyrosine kinases (RTKs), 24 RTKs, and 13 dual and other kinases, and compared the protein kinase expression profiles of hESCs and retinoic acidtreated hESCs. Significantly, up- and downregulated kinases in undifferentiated hESCs were confirmed by real-time PCR and western blotting. MAP3K3, ERBB2, FGFR4, and EPHB2 were predominantly upregulated, while CSF1R, TYRO3, SRC, and GSK3A were consistently downregulated in two hESC lines. Western blot analysis showed that the transcriptional levels of these kinases were consistent with the translational levels. The obstruction of upregulated kinases' activities using specific inhibitors disturbed the undifferentiated status and induced the differentiation of hESCs. Our results support the dynamic expression of PTKs during hESC maintenance and suggest that specific PTKs that are consistently up- and downregulated play important roles in the maintenance of stemness and the direction of differentiation of hESCs.

Reproduction (2008) 136 423-432
\end{abstract}

\section{Introduction}

Human embryonic stem cells (hESCs) have the ability to self-renew and differentiate into a variety of cell types within the three embryonic germ layers (Thomson et al. 1998). To identify the key molecules involved in maintaining stemness of hESCs, transcriptome characterization procedures, such as microarray (Ramalho-Santos et al. 2002, Sato et al. 2003, Sperger et al. 2003, Dvash et al. 2004), serial analysis of gene expression (Richards et al. 2004), and expressed sequence tags (ESTs; Brandenberger et al. 2004), have been employed. Molecules participating in several signaling pathways, including fibroblast growth factor (FGF), WNT, NODAL, PI3K/AKT, MAP kinase (MAPK)/ $E R K$, and NF- $K B$, may be involved in maintaining the stemness of hESCs (Sato et al. 2003, Brandenberger et al. 2004, Armstrong et al. 2006, Rho et al. 2006).

Generally, protein tyrosine kinases (PTKs) play pivotal roles in cell proliferation, apoptosis, oncogenesis, differentiation, and development (Hunter 1987). These proteins are among the key molecules that regulate signaling pathways, but only account for less than $10 \%$ of the total cellular kinases (Hunter 1994). PTKs are classified into receptor tyrosine kinases (RTK) and cytoplasmic non-RTKs (NRTK). In humans, 90 PTKs have been identified to date, comprising 58 receptor and 32 NRTKs (Robinson et al. 2000). Expression of most PTKs may be tightly regulated to retain unique features of a specific cell type. However, limited information is available on the molecular behavior of PTKs in hESCs.

Here, we present the PTK-focused expression profiles of hESCs. The transcriptional profiles of protein kinases (PKs) from hESCs are compared with those of retinoic acid (RA)-treated hESCs by an RT-PCR-based cloning technique using degenerate primers corresponding to the highly conserved catalytic domains of PTKs. We analyzed 1298 clones and identified 42 kinase genes in two genetically independent hESC lines. Our PTK profiling data should be valuable in understanding the 
A

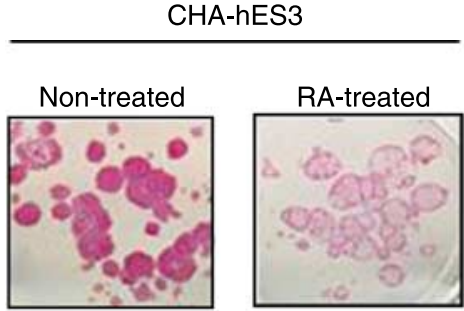

SNUhES3

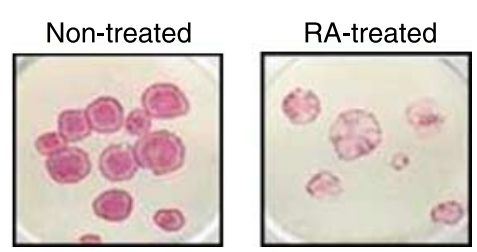

Non-treated-NANOG

$\square$ RA-treated-NANOG

[D Non-treated-(POU5F1)

B 1.2 व RA-treated-(POU5F1)

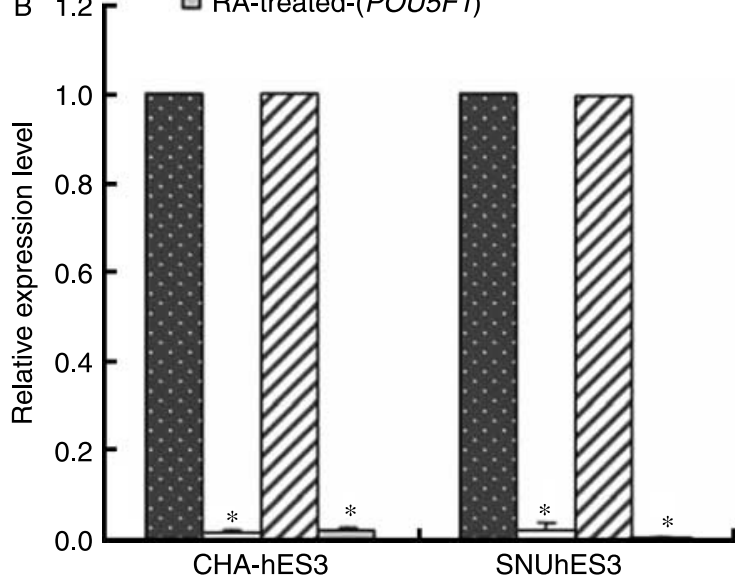

$\mathrm{R}$

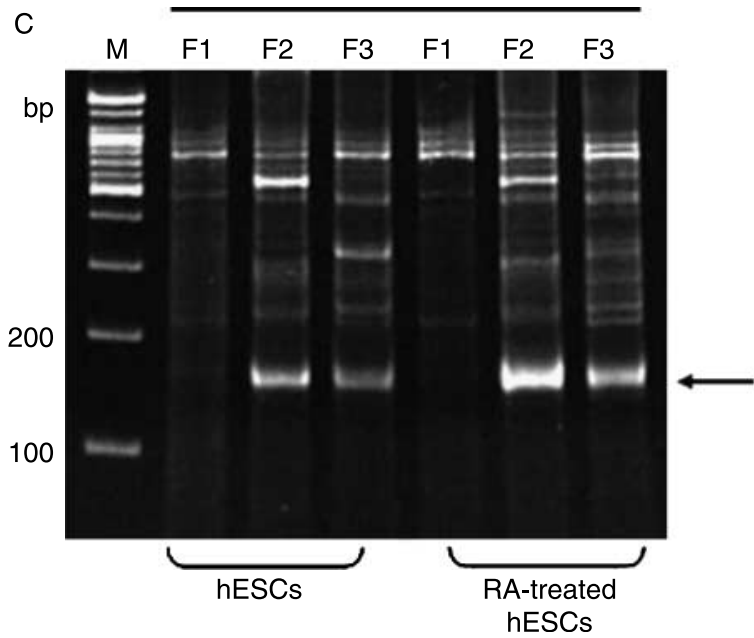

molecular mechanisms underlying the stemness, developing the novel biomarkers for the pluripotency, and identifying the potential regulators for differentiation in hESCs.

\section{Results}

\section{Identification of the tyrosine kinase family in hESCs}

To elucidate the molecular mechanisms of PTKs regulating the stemness of hESCs, differentiated cells were derived from the hESCs used as controls. To induce differentiation, hESCs were treated with RA for 5 days. As shown in Fig. 1A, alkaline phosphatase (AP) activity was considerably weak in RA-treated hESCs, compared with control hESCs. Moreover, transcriptional expression of stem cell marker genes, such as POU5F1 (OCT4) and NANOG, was remarkably reduced as assessed by realtime PCR (Fig. 1B). To assess the degree of diversity in differentiation capacity, we performed the real-time PCR analyses of the lineage markers for endoderm (amylase, albumin), mesoderm (GATA2), and ectoderm (NCAM). The RA-treated hESCs used in this study expressed diverse lineage markers (Supplementary Fig. 1, which can be viewed online at www.reproduction-online.org/supplemental). Thus, the RA treatment appeared to result in the loss of stemness with no preference for differentiation towards a specific lineage, consistent with a previous report (Draper et al. 2002). To determine the transcriptional patterns of PTKs, degenerate RT-PCR was performed in both control and RA-treated hESCs. Degenerate primers were designed on the basis of conserved motifs within the catalytic domains of tyrosine kinase, DFG and DVW. The DFG motif is present in all PK types; while DVW is primarily encoded by tyrosine kinases, but a small subset of serine/threonine kinases also contain the motif (Robinson et al. 1996, Lin et al. 1998). In this study, the forward (F1, F2, and F3) and reverse primer (R) are based on DFG and DVW motifs respectively (Supplementary Table 1, which can be viewed online at www.reproduction-online.org/supplemental). DNA fragments of 150-170 bp were successfully amplified by degenerate PCR (Fig. 1C). The F1-R combination yielded the least PCR products in two hESC lines. Similar results have been observed with other tissues and cell lines (Lin et al. 1998, Wu et al. 2000). We performed two independent degenerate PCRs for each hESC lines and pooled the amplification products together respectively,

Figure 1 Induction of hESC differentiation by retinoic acid (RA). (A) Alkaline phosphatase staining of hESC colonies. (B) Expression of hESC markers, POU5F1 and NANOG, by real-time PCR analysis. Statistical significance of data was assessed using Student's $t$-test $\left({ }^{*} P<0.01\right)$. (C) Representative gel electrophoresis of amplified protein tyrosine kinase RT-PCR products (150-170 bp). RT-PCR using a combination of degenerate primers, F1, F2, F3, and R, was performed, as described in the Materials and Methods section. 
for subsequent analysis. The pooled amplified products were eluted, cloned, and sequenced. BLASTN analyses revealed that $90.0 \%$ (743/826 clones) and $94.3 \%$ (445/ 472 clones) genes from CHA-hES3 and SNUhES3 encoded human PKs respectively (Table 1 ). Thus, we presented a high fidelity procedure for identifying PKs in hESCs. Among the identified genes, there were 36 and 31 non-redundant human kinase genes in CHA-hES3 and SNUhES3 respectively. Non-PKs were additionally detected, possibly as a result of PCR-related mispriming. Murine PKs were observed at a low frequency in both hESC types, which appear to be derived from feeder cells. Twenty-three human PTK genes and two serine/threonine kinases were commonly expressed in the two hESCs (Table 2).

\section{Differential expression of PK genes in hESCs}

To identify the candidate genes associated with the stemness of hESCs, expression profiles of PK genes in hESCs were compared with those of RA-treated hESCs by analyzing gene frequency (Table 2). In total, 386 clones from CHA-hES3 cells and 357 clones from RA-treated CHA-hES3 cells were assessed. Out of the 36 PKs identified in CHA-hES3 cells, 15 were transcriptionally upregulated and 19 were downregulated, compared with RA-treated CHA-hES3 cells. Two PK genes were equally expressed. Additionally, 228 clones from SNUhES3 cells and 217 clones from RA-treated SNUhES3 cells were analyzed. We identified 31 different PK genes in SNUhES3 cells. Of these, 17 PKs were transcriptionally upregulated and 14 were downregulated. In total, 42 kinases (including 5 NRTKs, 24 RTKs, and 13 dual and other kinases) were identified in $\mathrm{CHA}$ hES3 and SNUhES3 cells (Table 2). Out of the 42 genes, 11 (MAP3K3, ERBB2, FGFR4, EPHB2, CLK3, DDR1, MAP2K4, FGFR1, FGFR3, KDR, and MAP3K11) and 10 (CSF1R, TYRO3, SRC, GSK3A, PDGFRB, PLK4, ABL1,

Table 1 Identification of protein kinases (PKs) expressed in human embryonic stem cells (hESCs) by RT-PCR using degenerate primers.

\begin{tabular}{|c|c|c|c|c|}
\hline hESC lines & Category & Clones & $(\%)$ & Genes \\
\hline \multirow[t]{6}{*}{ CHA-hES3 } & Human $\mathrm{PKs}^{\mathrm{a}}$ & 743 & (90.0) & 36 \\
\hline & Murine $\mathrm{PKs}^{\mathrm{a}}$ & 4 & $(0.5)$ & 4 \\
\hline & Non-PKs & 79 & (9.6) & 41 \\
\hline & Known ${ }^{b}$ & 56 & & 21 \\
\hline & No hits ${ }^{\mathrm{C}}$ & 23 & & 20 \\
\hline & Total & 826 & & 81 \\
\hline \multirow[t]{6}{*}{ SNUhES3 } & Human $\mathrm{PKs}^{\mathrm{a}}$ & 445 & (94.3) & 31 \\
\hline & Murine $\mathrm{PKs}^{\mathrm{a}}$ & 6 & (1.3) & 3 \\
\hline & Non-PKs & 21 & (4.4) & 18 \\
\hline & Known ${ }^{b}$ & 17 & & 14 \\
\hline & No hits ${ }^{c}$ & 4 & & 4 \\
\hline & Total & 472 & & 52 \\
\hline
\end{tabular}
aProtein tyrosine kinases, dual specific kinases, and some serine/
threonine kinases are included. ${ }^{b}$ Genes of known function that are not
human PTK genes. ' No significant similarity to any known genes by
BLASTN.
EPHA2, EPHB3, and MERTK) were commonly up- and downregulated in both hESC lines respectively. The cellular functions of the kinase genes identified in this study are presented in Table 3. These PK profiles obtained using gene frequency analyses provide valuable information on the dynamic behavior of these proteins between undifferentiated and differentiated hESCs.

\section{Validation of selected tyrosine kinases by real-time PCR and western blotting}

To validate the differential expression of PK genes between normal and differentiated hESCs, further experiments were performed on several selected genes. Prior to choosing the genes for ensuing analyses, we needed to set up selection criteria because the two different hESC lines of different genetic backgrounds that we analyzed showed some variations in gene expression patterns and possibly in preferential differentiation potential, as reported previously (Abeyta et al. 2004, Skottman et al. 2005). We selected the genes using the following criteria: (i) The expression of genes should be commonly upand downregulated in both hESC lines respectively. (ii) Among commonly up- and downregulated genes, the significant $P$ values of the genes from the gene frequency analysis on PK expression profile should be lower than 0.01 in at least one of the two hESC lines. Based on this, we found that four upregulated (MAP3K3, ERBB2, FGFR4, and EPHB2) and four downregulated (CSF1R, TYRO3, SRC, and GSK3A) genes fitted the criteria (Table 3 ). To verify more quantitatively, eight selected kinases were analyzed by real-time PCR. Four PTK genes (MAP3K3, ERBB2, FGFR4, and EPHB2) were highly expressed in both CHA-hES3 and SNUhES3 cells, compared with RA-treated hESCs (Fig. 2A), whereas four selected genes (CSF1R, TYRO3, SRC, and GSK3A) displayed lower transcriptional levels in both hESC lines, compared with RA-treated hESCs (Fig. 2B). Thus, the expression patterns of kinase genes detected using gene frequency analysis were consistent with those determined from quantitative real-time PCR. It could be guessed that the differential expressions of the target kinase genes were observed uniquely from RA-directed differentiation but not from other general differentiation protocols. To test this possibility, we prepared embryoid bodies (EBs) from CHA-hES3, which are widely regarded as spontaneously differentiated cells representing a mixture of various cell types, and examined the target gene expression with them. The results of quantitative real-time PCR with EBs showed both up- and downregulated kinases to be similarly expressed respectively as the results with RA-treated samples (Supplementary Fig. 2, which can be viewed online at www.reproduction-online.org/supplemental). Thus, it might be assumed that expressions of eight selected kinases are not dependent on particular differentiation protocols. 


\begin{tabular}{|c|c|c|c|c|c|c|c|}
\hline \multirow[b]{2}{*}{ Kinase } & \multirow[b]{2}{*}{ Amino acid sequence } & \multicolumn{6}{|c|}{ Frequency $(\%)^{a}$} \\
\hline & & CHA-hES3 & $\begin{array}{l}\text { RA-treated } \\
\text { CHA-hES3 }\end{array}$ & $P E^{b}$ & SNUhES3 & $\begin{array}{l}\text { RA-treated } \\
\text { SNUhES3 }\end{array}$ & $P E^{a}$ \\
\hline \multicolumn{8}{|c|}{ Non-receptor PTK } \\
\hline$A B L 1$ & DFGLSRLMTGDT----YTAHAG-AKFPIKWTAP----ESLAYNK-----FSIKS--DVW & 18.7 & 21.3 & - & 7.9 & 16.1 & - \\
\hline FES & DFGMSREEADGV----YAASGGLRQVPVKWTAP----EALNYGR-----YSSES- -DVW & 0.8 & 2.0 & - & 2.6 & 0.5 & + \\
\hline JAK3 & DFGLAKLLPLDKDY --- YVVREPGQSPIFWYAP- $---\mathbf{E}$ SLSDNI ----- FSRQS -- DVW & 0.3 & 0.0 & + & 0.0 & 0.0 & NF \\
\hline$S R C$ & DFGLARLIEDNE----YTARQG-AKFPIKWTAP----EAALYGR-----FTIKS--DVW & 0.8 & 3.6 & - & 0.4 & 1.4 & - \\
\hline TYK2 & DFGLAKAVPEGHEY - --YRVREDGDSPVFWYAP----ECLKEYK-----FYYAS--DVW & 0.3 & 0.0 & + & 0.0 & 0.0 & NF \\
\hline \multicolumn{8}{|c|}{ 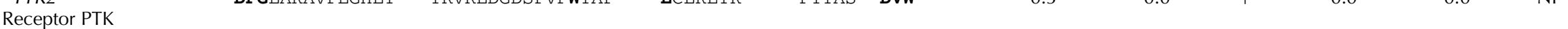 } \\
\hline CSF1R & DFGLARDIMNDSNY----IVKGNARLPVKWMAP----ESIFDCV-----YTVQS--DVW & 0.0 & 4.5 & - & 0.0 & 6.0 & - \\
\hline DDR1 & DFGMSRNLYAGDYY ---- RVQGRAVLPIRWMAW $----\mathbf{E}$ CILMGK ----- FTTAS -- DVW & 1.0 & 0.0 & + & 1.3 & 0.5 & + \\
\hline EPHA1 & DFGLTRLL--DDFDGTYETQ-G-GKIPIRWTAP----EAIAHRI-----FTTAS--DVW & 0.3 & 0.3 & - & 0.0 & 0.0 & NF \\
\hline EPHA2 & DFGLSRVLEDDP-EATYTTS-G-GKIPIRWTAP----EAISYRK-----FTSAS--DVW & 0.0 & 0.3 & - & 2.2 & 2.3 & - \\
\hline EPHA4 & DFGMSRVLEDDP-EAAYTTR-G-GKIPIRWTAP----EAIAYRK-----FTSAS--DVW & 0.0 & 0.0 & NF & 0.0 & 0.5 & - \\
\hline EPHB1 & DFGLSRYLQDDTSDPTYTSSLG-GKI PVRWTAP- - - -EAIAYRK-- - - FTSAS- - DVW & 1.6 & 0.0 & + & 0.4 & 0.5 & - \\
\hline EPHB2 & DFGLSRFLEDDTSDPTYTSALG-GKIPIRWTAP----EAIQYRK--- - -FTSAS- - DVW & 29.5 & 15.1 & + & 43.9 & 43.3 & + \\
\hline EPHB3 & DFGLSRFLEDDPSDPTYTSSLG-GKIPIRWTAP-- - -EAIAYRK-- - - FTSAS- -DVW & 0.0 & 0.8 & - & 0.0 & 0.5 & - \\
\hline EPHB4 & DFGLSRFLEENSSDPTYTSSLG-GKIPIRWTAP----EAIAFRK-----FTSAS--DAW & 0.0 & 0.3 & - & 0.0 & 0.0 & NF \\
\hline ERBB1 & DFGLAKLLGAEEKE---YHAEG-GKVPI KWMAL----ESILHRI--- - -YTHQS--DVW & 0.0 & 0.8 & - & 0.0 & 0.0 & NF \\
\hline ERBB2 & DFGLARLLDIDETE---YHADG-GKVPIKWMAL----ESILRRR--- - -FTHQS--DVW & 17.1 & 7.3 & + & 11.0 & 5.1 & + \\
\hline ERBB3 & DFGVADLLPPDDKQ - --LLYSE-AKTPIKWMAL- - - ESIHFGK-----YTHQS--DVW & 0.0 & 0.3 & - & 0.0 & 0.0 & NF \\
\hline FGFR1 & DFGLARDIHHIDYY----KKTTNGRLPVKWMAP----EALFDRI-----YTHQS--DVW & 6.5 & 5.0 & + & 2.6 & 0.9 & + \\
\hline FGFR3 & DFGLARDVHNLDYY ---- KKTTNGRLPVKWMAP- --- EALFDRV ----- YTHQS -- DVW & 1.0 & 0.6 & + & 0.4 & 0.0 & + \\
\hline FGFR4 & DFGLARGVHHIDYY ---- KKTSNGRLPVKWMAP----EALFDRV------YTHQS--DVW & 3.4 & 1.1 & + & 4.4 & 0.0 & + \\
\hline FGFRL1 & DFGGTTSFQCKVRS--DVKPVIQWLKRVEYGAEGRHNSTIDVGGQ---KFVVLPTGDVW & 0.3 & 0.3 & - & 0.0 & 0.0 & NF \\
\hline FLT4 & DFGLARDIYKDPDY ---- VRKGSARLPLKWMAP----ESIFDKV-----YTTQS- -DVW & 0.0 & 0.0 & NF & 0.4 & 0.0 & + \\
\hline INSRR & DFGMTRDVYETDYY ---- RKGGKGLLPVRWMAP- $---\mathbf{E}$ SLKDGI ----- FTTHS -- DVW & 0.5 & 0.6 & - & 0.9 & 0.0 & + \\
\hline$K D R$ & DFGLARDIYKDPDY - ---VRKGDARLPLKWMAP----ETIFDRV-----YTIQS--DVW & 0.5 & 0.0 & + & 0.4 & 0.0 & + \\
\hline MERTK & DFGLSKKIYSGDYY - - - RQGRIAKMPVKWIAI--- -ESLADRV----- YTSKS - - DVW & 0.0 & 0.3 & - & 0.0 & 0.5 & - \\
\hline MST1R & DFGLARDILDREYYS--VQQHRHARLPVKWMAL----ESLQTYR-----FTTKS--DVW & 0.0 & 0.3 & - & 0.0 & 0.0 & NF \\
\hline PDGFRA & DFGLARDIMHDSNY----VSKGSTFLPVKWMAP--- -ESIFDNL---- -YTTLS- - DVW & 0.0 & 0.0 & NF & 0.0 & 0.5 & - \\
\hline PDGFRB & DFGLARDIMRDSNY - - - - ISKGSTFLPLKWMAP--- -ESIFNSL- - - - YTTLS -- DVW & 0.3 & 2.5 & - & 0.0 & 0.9 & - \\
\hline TYRO3 & DFGLSRKIYSGDYY ---- RQGCASKLPVKWLAL $----\mathbf{E S L A D N L}-----$ YTVQS -- DVW & 1.8 & 14.8 & - & 2.2 & 11.5 & - \\
\hline \multicolumn{8}{|c|}{ 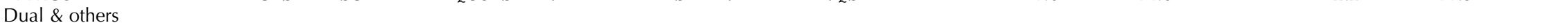 } \\
\hline$A R A F$ & DFGLATVKTRWSGA----QPLEQPSGSVLWMAA----EVIRMQDP--NPYSFQS--DVY & 0.0 & 0.0 & NF & 0.4 & 0.0 & + \\
\hline CAMKK2 & DFGVSNEFK---GS---DALLSNTVGTPAFMAP----ESLSETRK- - IFSGKAL- -DVW & 0.0 & 0.0 & NF & 0.4 & 0.0 & + \\
\hline CDK4 & 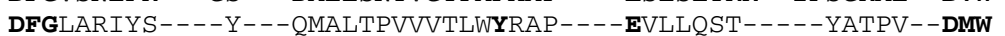 & 0.0 & 0.0 & NF & 0.0 & 0.5 & - \\
\hline CLK1 & DFGSA-TYD-- - -D---EH-HSTLVSTRHYRAP----EVILALG-----WSOPC--DVW & 0.0 & 0.6 & - & 0.0 & 0.0 & NF \\
\hline CLK3 & DFGSA-TFD----H---EH-HTTIVATRHYRPP----EVILELG-----WAQPC--DVW & 1.6 & 0.6 & + & 3.5 & 0.9 & + \\
\hline GSK3A & DFGSAKQLV----R---GEPNVSYICSRYYRAP----ELIFG----ATDYTSSI - -DVW & 2.8 & 11.2 & - & 2.2 & 4.6 & - \\
\hline ICK & DFGLAREIR----S---KPPYTDYVSTRWYRAP----EVLLRSTN----YSSPI--DVW & 0.0 & 0.6 & - & 0.0 & 0.0 & NF \\
\hline MAP2K3 & DFGISGYLV----D---SVAKTMDAGCKPYMAP----ERINP-ELNQKGYNVKS- -DVW & 1.3 & 0.0 & + & 0.0 & 0.0 & NF \\
\hline MAP2K4 & DFGISGQLV-- - -D---SIAKTRDAGCRPYMAP----ERIDP-SASRQGYDVRS--DVW & 1.6 & 0.3 & + & 1.8 & 0.5 & + \\
\hline MAP2K7 & DFGISGRLV----D---SKAKTRSAGCAAYMAP--- -ERIDPPDPTKPDYDIRA--DVW & 0.0 & 0.3 & - & 0.4 & 0.0 & + \\
\hline МАРЗКЗ & DFGASKRLQTICMS --- GTGMRSVTGTPYWMSP ---- EVISGEG ----- YGRKA -- DVW & 6.5 & 1.4 & + & 9.6 & 0.5 & + \\
\hline MAP3K11 & DFGLAREWHKTTQM----SAAG-- - TYAWMAP-- - -EVIKAST- - - - FSKGS- -DVW & 1.3 & 0.8 & + & 0.4 & 0.0 & + \\
\hline PLK4 & DFGLATOLK---MP---HEKHYTLCGTPNYISP----EIATRSA-- - - HGLES--DVW & 0.5 & 2.2 & - & 0.0 & 2.3 & - \\
\hline
\end{tabular}

${ }^{a}$ The frequency of each kinase was evaluated by dividing the number of clones of a kinase gene by the number of total clones of human origin from each sample. ${ }^{b} \mathrm{PE}$ indicates the patterns of

expression of a gene in hESC as follows; +, upregulated; - , downregulated; $\bullet$, equally expressed; NF, not found. 
Table 3 Up- and downregulated kinase genes in human embryonic stem cells (hESCs).

\begin{tabular}{|c|c|c|c|c|}
\hline \multirow[b]{2}{*}{ Gene } & \multirow[b]{2}{*}{ Gene description (Gene title) } & \multirow[b]{2}{*}{ Gene function ${ }^{b}$} & \multicolumn{2}{|c|}{$P$ value $^{a}$} \\
\hline & & & CHA3-hES3 & SNU3-hES3 \\
\hline \multicolumn{5}{|l|}{ Upregulated } \\
\hline$M A P 3 K 3$ & MAP kinase kinase kinase 3 & MAPKKK cascade & $P<0.001$ & $P<0.001$ \\
\hline ERBB2 & $\begin{array}{l}\text { v-erb-b2 erythroblastic leukemia viral } \\
\text { oncogene homolog } 2\end{array}$ & Cell proliferation & $P<0.001$ & $P<0.03$ \\
\hline FGFR4 & Fibroblast growth factor receptor 4 & Cell communication & $P<0.05$ & $P<0.002$ \\
\hline EPHB2 & EPH receptor B2 & Nervous system development & $P<0.001$ & \\
\hline CLK3 & CDC-like kinase 3 & Metabolism & & $P<0.08$ \\
\hline DDR1 & Discoidin domain receptor family, member 1 & Cell adhesion & $P<0.08$ & \\
\hline MAP2K4 & MAP kinase kinase 4 & JNK cascade & $P<0.09$ & \\
\hline FGFR1 & Fibroblast growth factor receptor 1 & Cell growth, skeletal development & & \\
\hline FGFR3 & Fibroblast growth factor receptor 3 & Cell growth, skeletal development & & \\
\hline$K D R$ & Kinase insert domain receptor & Cell fate commitment & & \\
\hline MAP3K11 & MAP kinase kinase kinase 11 & Cell proliferation, regulation of JNK cascade & & \\
\hline \multicolumn{5}{|c|}{ Downregulated } \\
\hline CSF1R & Colony-stimulating factor 1 receptor & Cell proliferation & $P<0.001$ & $P<0.001$ \\
\hline TYRO3 & TYRO3 protein tyrosine kinase & Cell adhesion & $P<0.001$ & $P<0.001$ \\
\hline$S R C$ & $\begin{array}{l}\text { v-src sarcoma (Schmidt-Ruppin A-2) viral } \\
\text { oncogene homolog }\end{array}$ & Cell communication & $P<0.001$ & \\
\hline GSK3A & Glycogen synthase kinase $3 \alpha$ & Metabolism & $P<0.001$ & $P<0.1$ \\
\hline PDGFRB & $\begin{array}{l}\text { Platelet-derived growth factor receptor, } \\
\beta \text {-polypeptide }\end{array}$ & Cell communication & $P<0.02$ & \\
\hline$P L K 4$ & Polo-like kinase 4 & Regulation of progression through cell cycle & $P<0.05$ & $P<0.03$ \\
\hline$A B L 1$ & $\begin{array}{l}\text { v-abl Abelson murine leukemia viral } \\
\text { oncogene homolog } 1\end{array}$ & $\begin{array}{l}\text { Intracellular signaling cascade, cell } \\
\text { adhesion }\end{array}$ & & \\
\hline EPHA2 & $\mathrm{EPH}$ receptor $\mathrm{A} 2$ & Neuron differentiation & & \\
\hline EPHB3 & $\mathrm{EPH}$ receptor $\mathrm{B} 3$ & Axon guidance & & \\
\hline MERTK & c-mer proto-oncogene tyrosine kinase & $\begin{array}{l}\text { Cell surface receptor linked signal } \\
\text { transduction }\end{array}$ & & \\
\hline
\end{tabular}

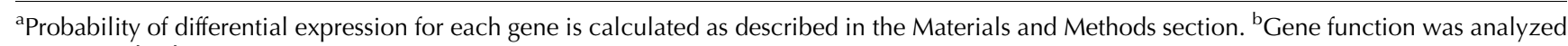
using GO database.

We further examined the expressions of eight selected kinases at protein level in CHA-hES3 cells. The stemness marker, POU5F1, expression was markedly decreased in RA-treated CHA-hES3 cells. Undifferentiated hESCs expressed higher levels of MAP3K3, ERBB2, FGFR4, and EPHB2. On the other hand, CSF1R, TYRO3, SRC, and GSK3A are abundant in RA-treated CHA-hES3 cells. Therefore, the transcriptional profiles of eight PKs were consistent with the translational profiles in CHA-hES3 cells (Fig. 2C). It should be noted, however, that the protein level does not always correlate to the protein activity, which raises the need for measuring the level of the phosphorylated form of each kinase.

\section{Effect of kinase inhibitors on the stemness of hESCs}

Among the kinase genes consistently expressed in hESCs, it is possible that the highly expressed genes, such as MAP3K3, ERBB2, FGFR4, and EPHB2, play important roles in maintaining the undifferentiated hESC state. To further establish whether PTKs affect the stemness of hESCs, CHA-hES3 cells were separately exposed to commercially available PTK-specific inhibitors under the feeder-free system (Fig. 3). Following treatment with AG825 (an inhibitor of ERBB2) and PD173074 (an inhibitor of FGFR) for 3 days respectively,
CHA-hES3 cells were morphologically differentiated (Fig. 3A) and showed weak AP activity (Fig. 3B) compared with the control group. POU5F1 and NANOG transcripts were significantly reduced in inhibitor-treated hESCs (Fig. 3C). Flow cytometry analyses using antibody recognizing either AP or SSEA4 verified the result once again. While more than $90 \%$ of the control, CHA-hES3 cells had positive signals for the two markers, only 44.94 and $57.58 \%$ of AG825treated cells and 34.09 and $26.64 \%$ of PD173074treated cells were positive for AP and SSEA4 respectively (Fig. 3D). Our results imply that the inhibition of either ERBB2 or FGFR4 activity leads to loss of stemness in hESCs, supporting the theory that PTKs are involved in maintaining the undifferentiated state of hESC.

\section{Discussion}

The PTK profiling approach presented in this report has been used in several other research fields and helps to figure out the contributions of PTKs especially in tumor tissue and cancer cell line (Robinson et al. 1996, Lin et al. 1998). We adapted PTK profiling approach to hESC and rapidly isolated some PTKs that contribute to maintain undifferentiated status in hESCs. A few reports on PTKs that play key roles in controlling self-renewal 
A

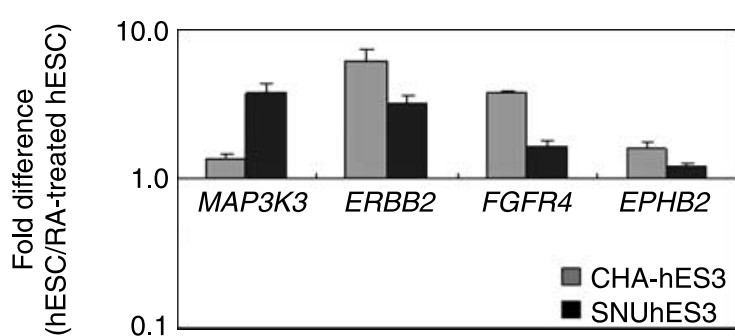

B

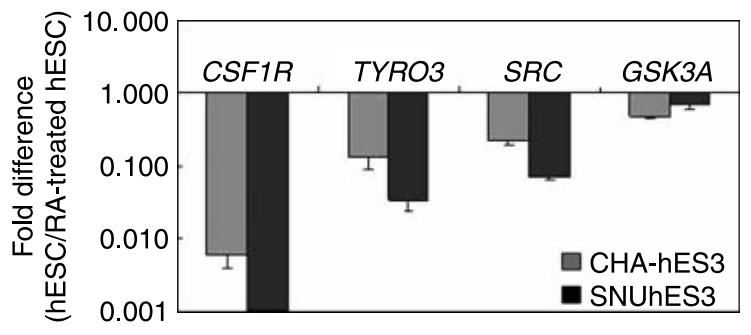

C hESCs RA-treated

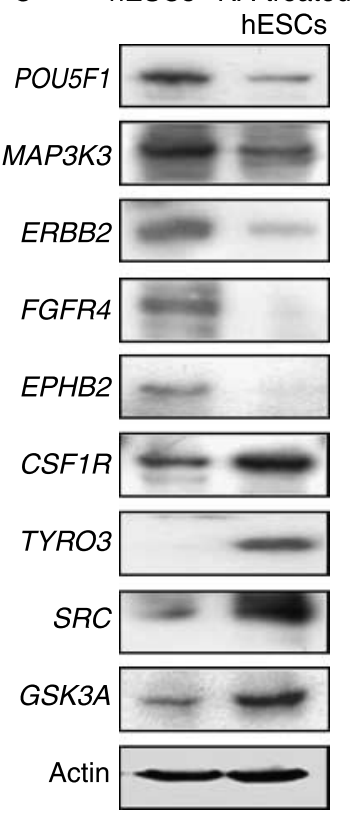

Figure 2 Verification of the up- and downregulation of protein kinase $(\mathrm{PK})$ genes in hESCs. Expression patterns of PK genes detected by gene frequency analysis were analyzed by real-time PCR. Four protein tyrosine kinase genes, MAP3K3, ERBB2, FGFR4, and EPHB2, were consistently upregulated in the two hESC lines, CHA-hES3 and SNU-hES3 (A), whereas four PK genes, CSF1R, TYRO3, SRC, and GSK3A, were consistently downregulated in two hESC lines (B). The expression levels of the PK genes in $\mathrm{hESCs}$ are compared, relative to levels in retinoic acid (RA)-treated hESCs, 1 representing unchanged expression and 0.1 signifying tenfold downregulation in hESCs. (C) Comparison of protein expression of selected kinases between undifferentiated hESC and differentiated hESCs. Twenty micrograms of each cell lysate from undifferentiated CHA-hES3 cells or RA-treated $\mathrm{CHA}-\mathrm{hES} 3$ cells were processed for the western blotting analysis using specific antibodies. Actin was used as loading control. and pluripotency in hESCs are available (Sato et al. 2003, Brandenberger et al. 2004, Skottman et al. 2005). These early studies demonstrate that FGF RTKs are related to the stemness of hESCs. In addition to FGF receptors (FGFRs), such as FGFR4, we also found that MAP3K3, ERBB2, EPHB2, CSF1R, TYRO3, SRC, and GSK3A were differentially expressed between undifferentiated and differentiated hESCs.

Among the PTKs described above, MAP3K3, ERBB2, $F G F R 4$, and EPHB2 were consistently upregulated in the undifferentiated state, but downregulated during differentiation (Fig. 2). Upregulation of these PTKs may be essential for maintaining the undifferentiated state of hESCs. FGFR is required to stimulate the phospholipase $\mathrm{C} \gamma, \mathrm{PI} 3 \mathrm{~K} / \mathrm{AKT}$, and MAPK/ERK pathways (Eswarakumar et al. 2005). As observed from microarray (Sato et al. 2003, Skottman et al. 2005) and EST frequency analyses (Brandenberger et al. 2004), FGF receptors are highly expressed in hESCs. Our gene frequency analyses using degenerate PCR disclosed that three (FGFR1, FGFR3, and FGFR4) of the four FGFRs (FGFR1-4) were highly transcribed in hESCs, compared with differentiated hESCs (Table 2). Basic FGF2 (bFGF) is an essential factor in maintaining the undifferentiated state of hESCs through the FGFR1, FGFR3, and FGFR4 pathways (Thomson et al. 1998, Brandenberger et al. 2004). It is possible that since FGFR4 is consistently upregulated in two hESC lines, this receptor is associated with FGF2 and acts on subsequent signal transduction cascades. Together with FGFR4, we found MAP3K3 and $E R B B 2$ also upregulated in undifferentiated hESCs. $M A P 3 K 3$ is a MAP kinase kinase kinase that activates the NF- $\kappa B$ and MAPK/ERK pathways (Zhang et al. 2006,
Kim et al. 2007). ERBB2, a member of the epithermal growth factor (EGF) family of RTKs, plays important roles in cell proliferation, survival and differentiation (Hung \& Lau 1999). ERBB2 has no ligand-binding domain, but binds tightly to other ligand-bound EGF receptor family members to enhance kinase-mediated activation of downstream signaling pathways, such as PI3K/AKT and MAPK/ERK (Holbro \& Hynes 2004). Microarray analysis revealed higher expression of ERBB2 in control hESCs than differentiated tissue samples (Sperger et al. 2003). The PI3K/AKT, MAPK/ERK, and NF- $\kappa$ B signaling pathways are crucial for the maintenance of pluripotency in hESCs (Armstrong et al. 2006). Since MAP3K3 and $E R B B 2$ function as active modulators in the $\mathrm{PI} 3 \mathrm{~K} / \mathrm{AKT}$, MAPK/ERK, and NF-KB signaling pathways, their upregulation is related to the stemness of hESCs. Interestingly, MAP3K3 and ERBB2 genes have binding sites for transcription factors, such as POU5F1, SOX2, and NANOG, upstream from the transcription initiation site (Boyer et al. 2005). Therefore, MAP3K3 and ERBB2 gene levels may be dependent on the expression of stem cell-specific factors, such as POU5F1, SOX2, and NANOG. In fact, the expression of MAP3K3 and $E R B B 2$ was considerably decreased in differentiated hESCs (Fig. 2C). EPHB2 RTK transcript levels were high in two hESC lines. EPH receptors, the largest known family of RTKs, are divided into two groups, based on the similarities in the extracellular domain sequences and affinities for binding ephrin-A and ephrin-B ligands, termed EphA and EphB respectively. The EPH/ephrin signaling pathway networks with the WNT signaling pathway during embryogenesis, tissue regeneration, and carcinogenesis (Katoh \& Katoh 2006). The canonical 
A
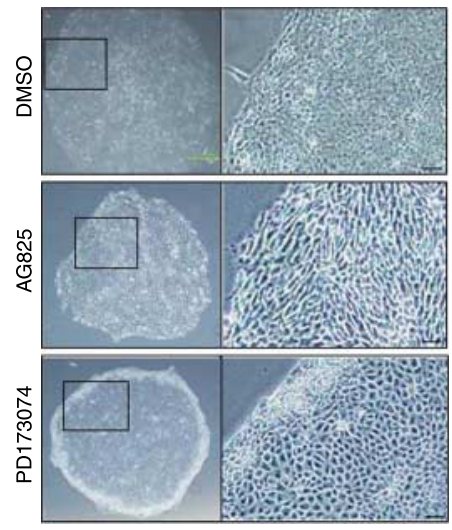

B
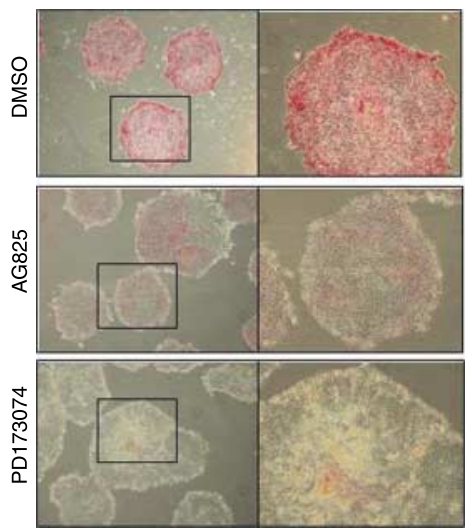

C
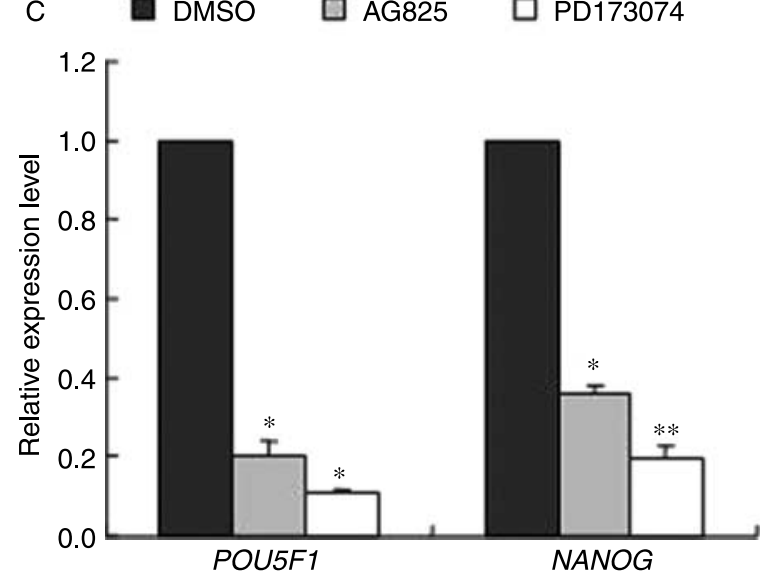

D

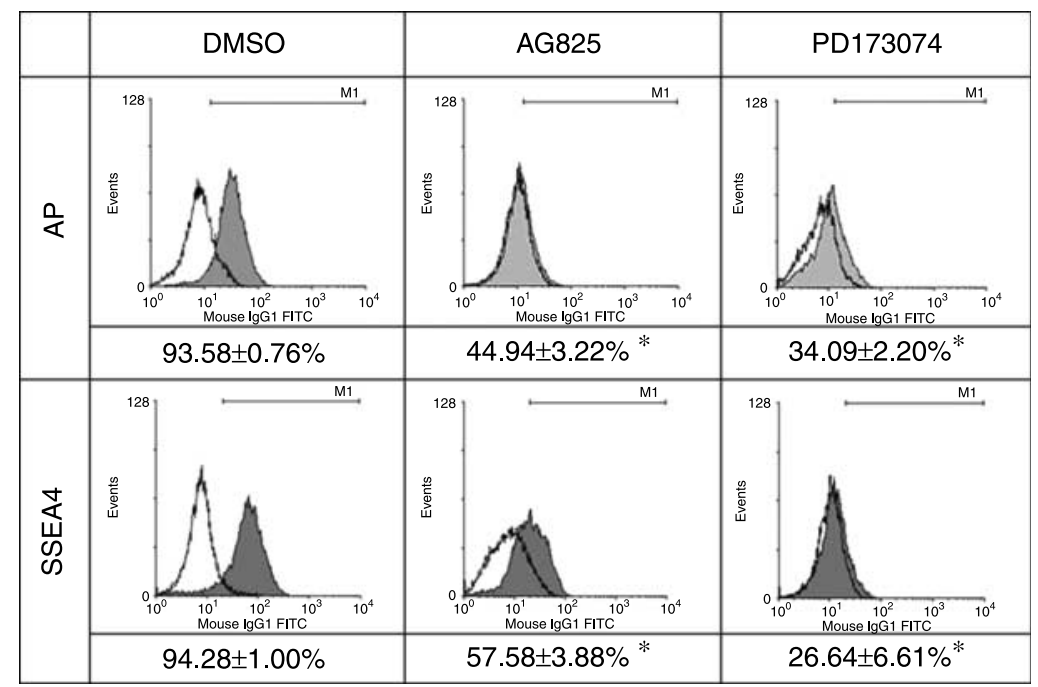

Figure 3 Effects of kinase inhibitors on the stemness in hESCs. CHA-hES3 cells were treated with inhibitors $(10 \mu \mathrm{M}$ for AG825 and $0.1 \mu \mathrm{M}$ for PD173074) specific for ERBB2 and FGFR4 respectively. (A) Inhibitor-treated hESCs were altered in appearance and (B) exhibited indeterminate alkaline phosphatase (AP) staining. (C) Transcriptional expression of POU5F1 and NANOG was significantly reduced in inhibitor-treated hESCs by real-time PCR analysis. The statistical significance of results was assessed using Student's $t$-test $(* P<0.05$, $\left.{ }^{* *} P<0.01\right)$. (D) Flow cytometric analysis of cells labeled with antibody to AP or SSEA4. Shown are representative plots of three independent experiments. The values (mean \pm S.E.M.) are the proportion of AP- or SSEA4-positive cells relative to total cells counted. Asterisks indicate that the values were significantly different from the value of DMSO control at $P<0.001$ level). Scale bars, $100 \mu \mathrm{m}$.
WNT signaling pathway has been reported to have a role in self-renewal of mouse and human ESCs (Sato et al. 2004). Therefore, the EPHB2 RTK may be involved in self-renewal through the canonical WNT signaling pathway.

On the other hand, CSF1R, TYRO3, SRC, and GSK3A were consistently downregulated in hESCs (Fig. 2). Thus, it is proposed that these kinase genes are repressed to retain the stemness of hESCs. CSF1R, a tyrosine receptor kinase for CSF1, mediates the survival, proliferation, differentiation, and functional modulation of mature blood cells and progenitors (Barreda et al. 2004). CSF1R is expressed during early hemangioblastic differentiation (Glasker et al. 2006). TYRO3 (also designated Sky, RSE), a member of the $A X L / T Y R O 3$ receptor family, is abundantly expressed in differentiating cells and tissues (Crosier et al. 1994). TYRO3 is essential for mammalian development and homeostatic maintenance of diverse 
cell populations in nervous, reproductive, and immune systems (Lu et al. 1999). However, the functions of CSF1R and TYRO3 in stem cells have not been established to date. The SRC family of cytoplasmic PTKs (SFKs), including SRC, LYN, FYN, YES, LCK, BLK, $H C K$, and $F G R$, plays important roles in cell proliferation, differentiation, and survival (Thomas \& Brugge 1997). SFK activity is required for initiating differentiation after LIF withdrawal in murine ESCs. In particular, $S R C$ is active during murine ESC differentiation (Meyn et al. 2005). In hESCs, SRC expression was increased in differentiated hESCs (Fig. 2). GSK3A was downregulated in undifferentiated hESCs. GSK3 contains two different isoforms, GSK3A and GSK3B, with 93\% catalytic domain sequence identity, and similar biochemical and substrate properties (Ali et al. 2001). Inhibition of GSK3 is required to maintain pluripotency in both mouse and human ESCs (Sato et al. 2004). These studies are in line with our observations. Altogether, our results suggest that downregulation of these genes is a prerequisite for the stemness.

The results from comparison of gene expression profiles between different hESC lines showed wide variations (Abeyta et al. 2004, Skottman et al. 2005). These variations between the hESC lines may be the result of dissimilar culture conditions and inherent genetic variations of embryos from which ESCs were derived. To cope with this problem, we have analyzed differences and similarities in gene expression profiles of two genetically independent $\mathrm{hESC}$ lines cultured in identical conditions. The technique of RT-PCR with degenerate primers appears to be an effective method for identification of differentially expressed PTKs in hESCs. However, different types of PTKs may be preferentially selected by using different combinations of degenerate primers, because several options exist in the design of degenerate primers. To overcome this bias of selection of PTKs based on the type of degenerate primers, further studies will be needed to capture a large number of different PTKs.

In this study, several key PTKs regulating the stemness of hESCs were successfully identified by gene frequency analysis using degenerate PCR. This is the comprehensive report on the expression profiles of PTKs involved in the stemness of hESCs. Our findings collectively indicate that kinase gene expression is dynamic and that these PTKs are tightly regulated during the maintenance and differentiation of hESCs.

\section{Materials and Methods \\ Culture and differentiation of hESCs}

Two hESC lines, CHA-hES3 and SNUhES3, were employed in this study. CHA-hES3 (Ahn et al. 2006) and SNUhES3 (Oh et al. 2005) were maintained in hESC medium on a feeder layer of mitomycin C-inactivated STO cells. The hESC medium consists of DMEM/F12 (Invitrogen) supplemented with 20\% serum replacement (Invitrogen), 1\% non-essential amino acids (Invitrogen), $1 \mathrm{mM}$ L-glutamine (Invitrogen), $0.1 \mathrm{mM}$ $\beta$-mercaptoethanol (Sigma-Aldrich), and $4 \mathrm{ng} / \mathrm{ml}$ bFGF (Invitrogen). HESCs were differentiated by treatment with $1 \mu \mathrm{M}$ RA (Sigma-Aldrich) for 5 days. Differentiated hESCs were verified by transcriptional reduction of stem cell-specific genes, such as POU5F1 and NANOG, and alkaline phosphatase (AP) staining. AP activity was measured using a specific staining kit, according to the manufacturer's protocol (Sigma-Aldrich).

\section{Analysis of the expression profiles of PTKs in hESCs}

Total RNA was extracted from hESCs using the RNeasy kit (Qiagen) and reverse transcribed (4 $\mu \mathrm{g})$ using the Superscript First-Strand Synthesis System (Invitrogen), according to the manufacturer's instructions. Degenerate PCR primers were based on the conserved DFG and DVW motifs of the tyrosine kinase catalytic domains VII and IX (Robinson et al. 1996, Lin et al. 1998). Three forward primers were designed from the following amino acid sequences: $\mathrm{F} 1\left(5^{\prime}-\mathrm{K}[\mathrm{V} / \mathrm{I}][\mathrm{S} / \mathrm{C}] \mathrm{DFG}-3^{\prime}\right), \mathrm{F} 2$ $\left(5^{\prime}-\mathrm{K}[\mathrm{V} / \mathrm{I}][\mathrm{G}] \mathrm{DFG}-3^{\prime}\right)$, and F3 (5'-K[V/I][A/T]DFG-3'). One reverse primer $(\mathrm{R})$ was designed from the sequence, $5^{\prime}$-DVW[S/A][F/Y]G-3' (Lin et al. 1998). The primers used in this study are listed in Supplementary Table 1 . The following PCR conditions were used: 5 cycles of $95^{\circ} \mathrm{C}$ for $1 \mathrm{~min}, 42^{\circ} \mathrm{C}$ for $1 \mathrm{~min}, 72{ }^{\circ} \mathrm{C}$ for $1 \mathrm{~min}$, followed by 25 cycles of $95{ }^{\circ} \mathrm{C}$ for $1 \mathrm{~min}, 50{ }^{\circ} \mathrm{C}$ for $1 \mathrm{~min}$, and $72{ }^{\circ} \mathrm{C}$ for $1 \mathrm{~min}$, and a final extension step at $72{ }^{\circ} \mathrm{C}$ for $10 \mathrm{~min}$. PCR products ranging from 150 to 170 bp were purified with the QIAquick Gel Extraction Kit (Qiagen) and directly subcloned into T-vector (Promega). Plasmid DNA from randomly selected positive clones were further purified with the Plasmid High-Throughput DNA Prep Kit (CoreBioSystem, Seoul, Korea) and sequenced with the ABI Prism 3700 DNA analyzer (PE Applied Biosystems, Foster City, CA, USA). Kinase gene sequences for individual clones were analyzed using BLASTN, with default parameters against the GenBank database from the National Center for Biotechnology Information. The frequency of each kinase was evaluated by dividing the number of clones of the kinase gene by the number of total clones of human origin from each sample. Significant differences in gene expression between data sets were calculated using the method of Audic \& Claverie (1997) (http://www.igs.cnrs-mrs.fr/Winflat/winflat.cgi).

\section{Quantitative real-time PCR}

Gene transcripts were quantitatively detected using SYBR Green (QuantiTect SYBR Green PCR Master Mix, Qiagen), according to the manufacturer's instructions, on the 7500 Real-Time PCR System (Applied Biosystems). Primers were designed using Primer3 software (http://frodo.wi.mit.edu/). Primer sequences are presented in Supplementary Table 1. To ensure the specificity and integrity of the PCR products, melting curve analyses were performed on all amplified products. The GAPDH level was used as the internal control, and fold changes were calculated according to the $2^{-\Delta \Delta C_{\mathrm{T}}}$ method (Livak \& Schmittgen 2001). All data were obtained in triplicate. 


\section{Western blotting analysis}

CHA-hES3 cells were lysed in RIPA buffer (50 mM Tris ( $\mathrm{pH} 8.0$ ), $150 \mathrm{mM} \mathrm{NaCl}, 1 \% \mathrm{NP}-40,0.1 \%$ SDS, $0.5 \%$ deoxycholic acid) containing $1 \mathrm{mM}$ PMSF and a cocktail of protease inhibitors. HESC lysates were incubated for $15 \mathrm{~min}$ on ice, and centrifuged at $20000 \mathrm{~g}$ for $10 \mathrm{~min}$ at $4{ }^{\circ} \mathrm{C}$. The supernatant was re-centrifuged for $10 \mathrm{~min}$, and protein concentrations were determined using the BCA method (Pierce, Rockford, IL, USA). Total proteins $(20 \mu \mathrm{g})$ were fractionated by SDS PAGE, and electrotransferred to polyvinylidene fluoride membranes (Millipore Corp, Bedford, MA, USA). Membranes were blocked in PBS supplemented with $0.1 \%$ Tween-20 and 5\% nonfat milk for $2 \mathrm{~h}$ at room temperature, and incubated overnight in primary antibodies, including anti-POU5F1 (sc-8629, Santa Cruz Biotechnology, Santa Cruz, CA, USA), anti-MAP3K3 (1673-1, Epitomics, Burlingame, CA, USA), anti-ERBB2 (2242, Cell Signaling Technology, Beverly, MA, USA), anti-FGFR4 (sc-124, Santa Cruz Biotechnology), anti-EPHB2 (sc-1763, Santa Cruz Biotechnology), anti-CSF1R (sc-692, Santa Cruz Biotechnology), anti-TYRO3 (sc-1095, Santa Cruz Biotechnology), anti-SRC (2109, Cell Signaling Technology), and anti-GSK3A (9338, Cell Signaling Technology). After incubation with the corresponding secondary anti-rabbit HRPconjugated or anti-mouse HRP-conjugated antibodies (Amersham), the membrane were developed using the ECL Advance kit (Amersham).

\section{Inhibitor treatment}

Inhibitors of ERBB2 (AG825) and FGFR4 (PD173074) were purchased from Calbiochem (Darmstadt, Germany) and Sigma respectively. CHA-hES3 cells were cultured in STO-conditioned medium supplemented with bFGF on Matrigel (BD Biosciences, Bedford, MA, USA) without feeder layers, as described previously (Xu et al. 2001). HESCs were treated with the respective inhibitors $(10 \mu \mathrm{M}$ for AG825 and $0.1 \mu \mathrm{M}$ for PD173074) for 3 days.

\section{Flow cytometry}

CHA-hES3 cells were dissociated in Cell Dissociation Buffer (Invitrogen), filtered through a $40 \mu \mathrm{m}$ nylon cell strainer (BD Biosciences Discovery Labware) and resuspended to about $5 \times 10^{5}$ cells in $100 \mu$ ldiluent containing $0.1 \%$ BSA in PBS. For analyzing ESC marker expression, cells were incubated with the primary antibodies, including IgG isotype control $(0.5 \mu \mathrm{g} / \mathrm{test}), \mathrm{AP}$ (R\&D systems, Inc., Minneapolis, MN, USA, cat. no. MAB1448, $1 \mu \mathrm{g} /$ test), and SSEA4 (R\&D systems, Inc., cat. no. MAB1435, $1 \mu \mathrm{g}$ /test) for $30 \mathrm{~min}$ at $4{ }^{\circ} \mathrm{C}$. After washing with $0.1 \%$ BSA in PBS, cells were incubated with fluorescein isothiocyanate (FITC)-conjugated goat anti-mouse IgG (Santa Cruz Biotechnology) for $30 \mathrm{~min}$ at $4{ }^{\circ} \mathrm{C}$ and finally stained with propidium iodide (Sigma) solution for $10 \mathrm{~min}$. Cells were washed and analyzed on FACSCalibur flow cytometer (Becton Dickinson, San Jose, CA, USA) using CellQuest software. A total of 10000 events were acquired, and analysis was limited to live events based on propidium iodide exclusion. The percentage of positive cells was assessed after correction for the percentage reactive to an isotype control conjugated to FITC.

\section{Declaration of interest}

The authors declare that there is no conflict of interest that could be perceived as prejudicing the impartiality of the research reported.

\section{Funding}

This research was supported by the Stem Cell Research Center of the 21st Century Frontier Research Program (SC2210) and KRCF/KRIBB (KGM1310811) Research Program.

\section{Acknowledgements}

We thank J-H Oh for valuable discussions and J-J Lee for technical support.

\section{References}

Abeyta MJ, Clark AT, Rodriguez RT, Bodnar MS, Pera RA \& Firpo MT 2004 Unique gene expression signatures of independently-derived human embryonic stem cell lines. Human Molecular Genetics 13 601-608.

Ahn SE, Kim S, Park KH, Moon SH, Lee HJ, Kim GJ, Lee YJ, Park KH, Cha KY \& Chung HM 2006 Primary bone-derived cells induce osteogenic differentiation without exogenous factors in human embryonic stem cells. Biochemical and Biophysical Research Communications $\mathbf{3 4 0}$ 403-408.

Ali A, Hoeflich KP \& Woodgett JR 2001 Glycogen synthase kinase-3: properties, functions, and regulation. Chemical Reviews 101 2527-2540.

Armstrong L, Hughes O, Yung S, Hyslop L, Stewart R, Wappler I, Peters H, Walter T, Stojkovic P, Evans J et al. 2006 The role of PI3K/AKT, MAPK/ERK and NFkappabeta signalling in the maintenance of human embryonic stem cell pluripotency and viability highlighted by transcriptional profiling and functional analysis. Human Molecular Genetics 15 1894-1913.

Audic S \& Claverie JM 1997 The significance of digital gene expression profiles. Genome Research 7 986-995.

Barreda DR, Hanington PC \& Belosevic M 2004 Regulation of myeloid development and function by colony stimulating factors. Developmental and Comparative Immunology 28 509-554.

Boyer LA, Lee TI, Cole MF, Johnstone SE, Levine SS, Zucker JP, Guenther MG, Kumar RM, Murray HL, Jenner RG et al. 2005 Core transcriptional regulatory circuitry in human embryonic stem cells. Cell 122 947-956.

Brandenberger R, Wei H, Zhang S, Lei S, Murage J, Fisk GJ, Li Y, Xu C, Fang R, Guegler K et al. 2004 Transcriptome characterization elucidates signaling networks that control human ES cell growth and differentiation. Nature Biotechnology 22 707-716.

Crosier PS, Lewis PM, Hall LR, Vitas MR, Morris CM, Beier DR, Wood CR \& Crosier KE 1994 Isolation of a receptor tyrosine kinase (DTK) from embryonic stem cells: structure, genetic mapping and analysis of expression. Growth Factors 11 125-136.

Draper JS, Pigott C, Thomson JA \& Andrews PW 2002 Surface antigens of human embryonic stem cells: changes upon differentiation in culture. Journal of Anatomy 200 249-258.

Dvash T, Mayshar Y, Darr H, McElhaney M, Barker D, Yanuka O, Kotkow KJ, Rubin LL, Benvenisty N \& Eiges R 2004 Temporal gene expression during differentiation of human embryonic stem cells and embryoid bodies. Human Reproduction 19 2875-2883.

Eswarakumar VP, Lax I \& Schlessinger J 2005 Cellular signaling by fibroblast growth factor receptors. Cytokine and Growth Factor Reviews 16 139-149. 
Glasker S, Li J, Xia JB, Okamoto H, Zeng W, Lonser RR, Zhuang Z, Oldfield EH \& Vortmeyer AO 2006 Hemangioblastomas share protein expression with embryonal hemangioblast progenitor cell. Cancer Research 66 4167-4172.

Holbro T \& Hynes NE 2004 ErbB receptors: directing key signaling networks throughout life. Annual Review of Pharmacology and Toxicology 44 195-217.

Hung MC \& Lau YK 1999 Basic science of HER-2/neu: a review. Seminars in Oncology 26 51-59.

Hunter T 1987 A thousand and one protein kinases. Cell 50 823-829.

Hunter T 19941001 protein kinases redux-towards 2000. Seminars in Cell Biology 5 367-376.

Katoh M \& Katoh M 2006 Comparative integromics on Eph family. International Journal of Oncology 28 1243-1247.

Kim K, Duramad O, Qin XF \& Su B 2007 MEKK3 is essential for lipopolysaccharide-induced interleukin- 6 and granulocyte-macrophage colony-stimulating factor production in macrophages. Immunology $\mathbf{1 2 0}$ 242-250.

Lin JS, Lu CW, Huang CJ, Wu PF, Robinson D, Kung HJ, Chi CW, Wu CW, Yang WK, Whang-Peng JJ et al. 1998 Protein-tyrosine kinase and proteinserine/threonine kinase expression in human gastric cancer cell lines. Journal of Biomedical Science 5 101-110.

Livak KJ \& Schmittgen TD 2001 Analysis of relative gene expression data using real-time quantitative PCR and the $2(-$ Delta Delta $\mathrm{C}(\mathrm{T}))$ method. Methods 25 402-408.

Lu Q, Gore M, Zhang Q, Camenisch T, Boast S, Casagranda F, Lai C, Skinner MK, Klein R, Matsushima GK et al. 1999 Tyro-3 family receptors are essential regulators of mammalian spermatogenesis. Nature $\mathbf{3 9 8}$ $723-728$.

Meyn MA III, Schreiner SJ, Dumitrescu TP, Nau GJ \& Smithgall TE 2005 SRC family kinase activity is required for murine embryonic stem cell growth and differentiation. Molecular Pharmacology 68 1320-1330.

Oh SK, Kim HS, Ahn HJ, Seol HW, Kim YY, Park YB, Yoon CJ, Kim DW, Kim SH \& Moon SY 2005 Derivation and characterization of new human embryonic stem cell lines: SNUhES1, SNUhES2, and SNUhES3. Stem Cells 23 211-219.

Ramalho-Santos M, Yoon S, Matsuzaki Y, Mulligan RC \& Melton DA 2002 'Stemness': transcriptional profiling of embryonic and adult stem cells. Science 298 597-600.

Rho JY, Yu K, Han JS, Chae JI, Koo DB, Yoon HS, Moon SY, Lee KK \& Han YM 2006 Transcriptional profiling of the developmentally important signalling pathways in human embryonic stem cells. Human Reproduction 21 405-412.
Richards M, Tan SP, Tan JH, Chan WK \& Bongso A 2004 The transcriptome profile of human embryonic stem cells as defined by SAGE. Stem Cells $\mathbf{2 2}$ 51-64.

Robinson D, He F, Pretlow T \& Kung HJ 1996 A tyrosine kinase profile of prostate carcinoma. PNAS 93 5958-5962.

Robinson DR, Wu YM \& Lin SF 2000 The protein tyrosine kinase family of the human genome. Oncogene 19 5548-5557.

Sato N, Sanjuan IM, Heke M, Uchida M, Naef F \& Brivanlou AH 2003 Molecular signature of human embryonic stem cells and its comparison with the mouse. Developmental Biology $260404-413$.

Sato N, Meijer L, Skaltsounis L, Greengard P \& Brivanlou AH 2004 Maintenance of pluripotency in human and mouse embryonic stem cells through activation of Wnt signaling by a pharmacological GSK-3-specific inhibitor. Nature Medicine 10 55-63.

Skottman H, Mikkola M, Lundin K, Olsson C, Stromberg AM, Tuuri T, Otonkoski T, Hovatta O \& Lahesmaa R 2005 Gene expression signatures of seven individual human embryonic stem cell lines. Stem Cells 23 1343-1356.

Sperger JM, Chen X, Draper JS, Antosiewicz JE, Chon CH, Jones SB, Brooks JD, Andrews PW, Brown PO \& Thomson JA 2003 Gene expression patterns in human embryonic stem cells and human pluripotent germ cell tumors. PNAS 100 13350-13355.

Thomas SM \& Brugge JS 1997 Cellular functions regulated by Src family kinases. Annual Review of Cell and Developmental Biology 13 513-609.

Thomson JA, Itskovitz-Eldor J, Shapiro SS, Waknitz MA, Swiergiel JJ, Marshall VS \& Jones JM 1998 Embryonic stem cell lines derived from human blastocysts. Science 282 1145-1147.

Wu CW, Li AF, Chi CW, Huang CL, Shen KH, Liu WY \& Lin W 2000 Human gastric cancer kinase profile and prognostic significance of MKK4 kinase. American Journal of Pathology 156 2007-2015.

Xu C, Inokuma MS, Denham J, Golds K, Kundu P, Gold JD \& Carpenter MK 2001 Feeder-free growth of undifferentiated human embryonic stem cells. Nature Biotechnology 19 971-974.

Zhang D, Facchinetti V, Wang X, Huang Q, Qin J \& Su B 2006 Identification of MEKK2/3 serine phosphorylation site targeted by the Toll-like receptor and stress pathways. EMBO Journal 25 97-107.

Received 21 February 2008

First decision 2 April 2008

Revised manuscript received 18 June 2008

Accepted 25 June 2008 